\title{
Ionizing Radiation
}

National Cancer Institute

\section{Source}

National Cancer Institute. Ionizing Radiation. NCI Thesaurus. Code C17052.

High-energy radiation capable of producing ionization in substances through which it passes. 